УДК $130.2: 316.75$

ББК $87.5+71.07$

DOI 10.25281/2072-3156-2018-15-1-21-31

\title{
Н.Е. СУДАКОВА
}

\section{ИНКЛЮЗИЯ КАК ЦЕННОСТНОЕ ЯДРО ФИЛОСОФИИ ГУМАНИЗМА}

\author{
Наталия Евгеньевна Судакова, \\ Российская академия народного хозяйства \\ и государственной службы \\ при Президенте Российской Федерации, \\ Институт государственной службы и управления, \\ кафедра ЮНЕСКО, \\ докторант \\ Вернадского пр., д. 84, Москва, 119606, Россия \\ кандидат педагогических наук \\ E-mail: sovetnik.imtp@mail.ru
}

Реферат. Социокультурные трансформации, затронувшие сегодня все пласты человеческого бытия, обостряют проблему включения в социальную жизнь Другого. В качестве ответа на нетерпимое отношение человека к человеку рождается новый феномен культуры - инклюзия, потребность в культурфилософской рефлексии которой предопределяет актуальность данной работы. Инклюзивные практики, общепринятое понимание которых кониентрирует внимание на деструктивном характере социильного взаимодействия общества и личности с ограниченными возможностями здоровья, требуют пересмотра своих смыслообразующих координат.

Обновленное понимание инклюзии как ядра философии гуманизма расширяет рамки мнения о том, что технологии удовлетворения обществом особых соиуиокультурных и образовательных потребностей должны быть обращены к людям с ограниченными возможностями здоровья, смешая акиенты в сторону признания «особливости»/уникальности каждой личности для дальнейшего развития человеческой цивилизации. Авторский подход, предоставляя каждому неограниченные возможности для самореализации, погружает человека в удивительное таинство творчества, устремленного к созиданию радости совместного бытия. Подчеркивается понимание творчества как процесса социиального взаимодействия, при котором лишение сверхиенности бытующих в современном обществе парадигм соперничества и результативности способствует преодолению негативных практик осознания себя/Другого как носителя анормальности, а также утверждению значимости «особливости»/ уникальности индивида для социильного благополучия человека и общества. Представленный подход $\kappa$ инклюзии, аккумулируя кониептуальные смыслы философии гуманизма, позволяет человеку открывать в себе уникальное начало, что способствует как социализации личности, так и обретению новых смыслов для существования. Обращение к последним исследованиям в области нейробиологии, доказывающим социальную природу человека, продиктовано недостаточным вниманием современного общества к воспитанию социиально ответственной личности. Социальная наполненность жизни человека, ведущая к утверждению собственной уникальной природы посредством включения в процеес сотворчества, способствуя преодолению кризиса смысла жизни, гармонизирует жизнедеятельность всех социальных институтов, в том числе в масштабе человечества.

Ключевые слова: инклюзия, гуманизм, человек, социум, культура, идентичность, Другой, люди с ограниченными возможностями здоровья, таинство творчества.

Для цитирования: Судакова Н.Е. Инклюзия как ценностное ядро философии гуманизма // Обсерватория культуры. 2018. Т. 15, № 1. C. $21-31$. DOI: 10.25281/2072-3156-2018-15-1-21-31.

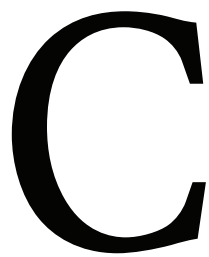

тремительно растущий интерес к феномену инклюзии вызван глобальными межцивилизационными социокультурными трансформациями, обусловленными осознанием значимости всеобщего признания «гуманистического культурного ренессанса» [1, с. 8] основой гармонизации общественной жизни. Очевидно, что «начало третьего тысячелетия - повод 
переосмыслить условия человеческого существования, задаться вопросом, куда завели нас наши маршруты и какими путями мы намерены двигаться дальше» [2], чем продиктована актуализация культурфилософской рефлексии данной проблемы.

Переживаемый современным социумом взрыв потребности в гуманизме вследствие повышения спроса на личностную значимость, свободу мировоззренческого, социокультурного и религиозного самоопределения выдвигает на первый план новые феномены. Инклюзия заявляет о себе как «качественно новое мировоззренческое представление о сущности и предназначении человеческой жизни, обозначающее не только признание единых прав на образование, жизнедеятельность и социализацию всех людей вне зависимости от их индивидуальных особенностей, но и высочайшую общечеловеческую ценность данных особенностей для дальнейшего развития человеческой цивилизации» [3, с. 160]. Данная дефиниция инклюзии опирается на общепринятое ее понимание, обозначенное А.Ю. Шемановым как социальная «модель отношений индивида и общества, которая рассматривает принятые в обществе ограничения в отношении различных категорий людей (инвалидов, мигрантов и т. д.) как социальные конструкции, выражающие не особенности данных людей, а характер создаваемых и циркулирующих в социуме дискурсивных образований» [4, с. 7; 5].

\section{ОНТОЛОГИЯ ИНКЛЮЗИИ: ЧЕЛОВЕК И СОЦИУМ}

$\mathrm{O}$ сознавая, что «существование в мире деструктивных сил, в первую очередь международного терроризма, националистического и религиозного фанатизма, наличие ядерного и бактериологического оружия, не уменьшает, а только усиливает значение гуманизма, который готов взять на себя ответственность за продолжение в новых формах и новыми средствами реализации великого проекта Просвещения, неотделимого от науки, демократии и защиты прав человека» [6, c. 8-9], констатируем, что данный контекст прирастает сегодня проблематикой отношения человека к Другому, где личностные различия проступают особенно ярко, влияя как на характер, так и на результат социального взаимодействия.

Изменения социокультурных доминант находят свое отражение во всех областях нашей жизни, что особенно убедительно звучит в различных текстах культуры. «Несуществующий народ» - название книги российского правозащитника и публициста Б.3. Кривошея (его сын родился с синдромом Дауна), которое очень точно отражает сущность человеческой жизни отвергнутых обществом людей, суть социальной эксклюзии, на протяжении веков бытующей в общественном сознании [7; 8]. Современная действительность еще больше отделила людей с ограниченными возможностями здоровья (OB3), а также тех, кто не имеет возможности по каким-либо причинам встроиться в социум, от людей, обладающих достаточными, а иногда практически неограниченными ресурсами для самореализации. Когда одни систематически находятся в центре событий, могут беспрепятственно перемещаться с одного континента на другой, имеют возможности для удовлетворения своих даже самых экзотических потребностей, другие не могут просто выйти из дома, или обречены на пожизненное заключение в интернатах, или вообще живут на улице. С появлением инклюзивных практик в российской культуре можно свидетельствовать, что изгои, не совершившие никаких аморальных поступков, но по тем или иным причинам выпавшие из социокультурного пространства, обозначенные исследователями как Другие, впервые получили сегодня возможность быть принятыми современным обществом.

Наблюдая перемену отношения к Другому вследствие интенсификации трансформаций этнодифференцирующих признаков, способствующих распространению феномена бикультуральности и множественности идентичности [9], можно отметить активизацию процессов, затрагивающих самую суть идентичности, ее этнокультурную принадлежность.

Если исходить из понимания того, что «идентичность человека с определенной общностью реализуется прежде всего через усвоение им представлений, норм, ценностей, образцов поведения, образующих ее культуру» [9, с. 6], то напрашивается вывод о том, что современные процессы универсализации ценностей, обозначенные как «переоценка ценностей и перестановка слагаемых ее духовно-смыслового ядра» [9, с. 7], преодолевая границы этноцентризма «в поиске новых точек соприкосновения между культурным разнообразием и всеобщими ценностями» [10, с. 100], способствуют активному созданию нового уровня социокультурного пространства, названного М.Н. Эпштейном как «транскультура» [11].

В данном контексте все ярче прорисовывается новая модель идентичности, основанная на многослойном процессе бытования как национальных, так и транснациональных поликультурных практик [12], где «положительная сторона развертывающихся сегодня процессов связана с тем, что глобализация социальных связей людей выводит их за пределы определенного культурного ареала, приобщает их к эталонам других культур» [9, с. 7]. Одним из феноменов приобщения к другой культуре может служить пример включения в российские образовательные практики в 1990-х гг. инклюзивных подходов. Именно путем обращения к изучению и вне- 
дрению инклюзивных образовательных практик, бытующих в разных странах Европейского Союза и США [13-16], пришла в отечественную культуру модель социализации детей с ОВ3, построенная на безоговорочном и безусловном включении их в единое образовательное пространство.

Данная модель до сих пор (когда уже существует законодательная база для ее применения в отечественном образовании) вызывает значительное количество дискуссий, чему есть объективные причины. Сегодня, в ситуации все усугубляющегося экономического кризиса, многие «благие намерения», в том числе передовые образовательные тенденции, воплощаются в жизнь сообразно идеям оптимизации. Некоторые исследователи, а также педагогическое сообщество выносят на обсуждение проблему замены специального образования, требующего серьезных государственных ресурсов, когда «бюджет специального образовательного учреждения в разы превышает стоимость обучения ребенка с инвалидностью в массовой школе» формальной инклюзией $[17$, с. 6]. Противовесом формализму может служить другая модель инклюзии, «которая не сводится к «реформированию школ и перепланировке учебных помещений» $[17$, с. 12$]$, обеспечивая ребенку комфортное существование в учебном заведении. Эта модель школы, где отсутствуют любые барьеры, в первую очередь психологические, укомплектованная педагогами, обладающими специальными знаниями в области нарушений, с которыми им пришлось столкнуться, достаточными методическими и техническими ресурсами для работы с детьми, имеющими ОВ3 [17], модель, ориентированная на пестование индивидуальности ребенка. Современная экономическая ситуация способствует формализации инклюзивных подходов, отсутствию ориентированности на ребенка, на удовлетворение его особых индивидуальных потребностей, возвращаясь тем самым в тот контекст, выходом из которого и была сама идея инклюзивности бытия, что активизирует дискуссионность данной проблематики. Формализация инклюзии не только мешает становлению инклюзивного сообщества, где будут реализованы способности всех без исключения в контексте ответственности за социальное благо, но, унифицируя подход к человеку, исключает из поля зрения его уникальность как основу инклюзивной культуры, фактически девальвируя весь ее ценностный потенциал.

Таким образом, очевидно, что столь значимый для общества социокультурный феномен как инклюзия реализуется сегодня в кризисном контексте, где, «с одной стороны, безбрежное "разбегание векторов”, которое, казалось бы, можно расценивать как проявление полной свободы в созидании культуры. С другой - не менее активное возвращение к забытым моделям и практикам. И первое, и второе в совокупности задает некий “скрытый алгоритм” противостояния» [18, с. 71]. Такое противостояние формальных и неформальных подходов усугубляет сегодня положение Другого в современном социуме.

Традиционные для отечественной культуры подходы к обучению детей-инвалидов в специализированных учреждениях достаточно долгое время являлись единственной возможностью получить образование ребенку с ОВЗ. Несмотря на серьезную научную базу и существующий практический опыт ее применения, данные образовательные методики были доступны далеко не всем детям. Большинство коррекционных учреждений находились вдалеке от места жительства детей, а потому обучавшиеся в них дети были оторваны от своей семьи, что, несомненно, сказывалось на их личностных и ценностных ориентирах. Упор на так называемую компенсацию нарушений, позволяющую человеку функционировать в обществе, создавал серьезные проблемы, обусловленные социальной изоляцией и препятствовал преодолению личностных кризисов. Социальные и ценностные ориентации человека начинаются с семьи, поэтому, отрывая ребенка от родителей, невозможно воспитать нравственно «здоровую» социально ответственную личность, способную заботиться о себе и своих близких.

Для решения этих проблем в отечественном образовании, в порядке эксперимента, о реализации которого подробно рассказывают Н.Н. Малофеев и Н.Д. Шматко [19], были созданы новые модели интеграции детей с ОВ3: полная постоянная интеграция (1-3 ребенка с ОВЗ постоянно находятся в среде здоровых сверстников); постоянная неполная интеграция (2-3 ребенка с ОВ3 дозированно находятся в среде здоровых сверстников, которых периодически объединяют вместе с другими детьми, имеющими ОВ3, для проведения занятий дефектологом); постоянная частичная интеграция (1-3 ребенка с ОВЗ вводятся на часть дня в группы здоровых сверстников); эпизодическая (направленная на эпизодическое взаимодействие детей с ОВ3 со здоровыми сверстниками в разных формах с целью социализации). Данные модели ориентированы на единую систему стандартизации образования, где значимым условием является приближенное к возрастной норме развитие ребенка с ОВЗ [19]. Для достижения результатов все силы педагогического сообщества направлялись на серьезную реабилитацию ребенка, на развитие его компенсаторных функций. Обозначенный подход позволял ребенку с ОВ3, «подстроившись» под здоровых сверстников, стать полноценным участником образовательного процесса, достичь серьезных жизненных результатов. Ориентация на полноценное усвоение единых образовательных стандартов детьми с ОВ3 как основа интегрированного подхода оставляла 
«за бортом» детей, не способных в момент обучения к унифицированной результативности, поскольку результаты детей с ОВ3 в общей своей массе не могут конкурировать с показателями других детей и носят весьма индивидуальный характер.

Обучение детей с ОВЗ является процессом «роста над самим собой», над совершенствованием тех или иных навыков, которые очень часто не являются проблемой для здоровых людей. Направленность на инклюзивный подход, обусловленный включением всех детей в единое образовательное пространство с целью их социализации, с условием индивидуализации траекторий развития каждого ребенка, ориентацией на его особые потребности, выделением достаточных ресурсов на реализацию этого подхода на практике, с одной стороны, и созидание инклюзивного сообщества, исповедующего ценности терпимости и толерантности к Другому, с другой стороны, позволяют решить ряд значимых проблем, связанных как с социокультурным выпадением людей с ОВЗ и всех, кто с трудом вписывается в обозначенные обществом рамки, так и с усугублением личностных кризисов вследствие осознания себя как Другого.

В данном контексте еще яснее становится понимание того, что наличие инклюзивной культуры как культуры принимающего сообщества является необходимым условием существования человечества. Это особенно актуально в сложившейся сегодня ситуации, определенной Всемирной организацией здравоохранения как инвалидизация человечества, поскольку более миллиарда людей на планете имеют сегодня инвалидность [20]. Скольким людям требуется подход, учитывающий их индивидуальные потребности, связанные с какими-либо ограничениями в области здоровья, еще предстоит осмыслить, но, очевидно, что их значительно больше, а потому игнорирование данной проблемы сегодня уже просто неприемлемо.

Российская цивилизация постепенно преодолевает негативное отношение к людям с ОВЗ вследствие становления транскультурной парадигмы в современном мире, провозглашающей всеобщую переоценку ценностей, направленную на активное распространение идей толерантности, инклюзии и всеобщего равенства. Мир инклюзии наполняется сегодня совершенно иным отношением к Другому. Победа Даниила Плужникова в российском телевизионном вокальном проекте «Голос. Дети» позволила по-новому взглянуть на безграничный потенциал людей с ОВЗ и повлекла за собой ряд событий, символизирующих вхождение российского общества в эпоху инклюзии. Еще 10 лет назад не могло быть и речи о том, что нашу страну на международном конкурсе песни «Евровидение» будет представлять вокалистка с серьезным генетическим заболеванием. Но сегодня известно, что Юлия Самойлова, не только самобытная российская исполнительница, но и поистине стойкая духом женщина, преодолевающая все тяготы неизлечимого заболевания, будет представлять Россию в Лиссабоне на конкурсе «Евровидение-2018» (несмотря на отказ во въезде в Украину в 2017 г. для участия в конкурсе).

Соглашаясь с А.Ю. Шемановым, что личностная идентификация невозможна без ответа на вопрос «Кто я?»/«Что я собой представляю?», ответить на который можно «лишь определив, что такое действительность в целом, каков мир, в котором я живу» [21, с. 54], мы неизменно возвращаемся к краеугольной проблеме смысла человеческого существования, ценность которого определяется наличием или отсутствием социума как такового. Недостаток возможности проявить себя в социокультурном пространстве сводит на нет сам смысл человеческой жизни, приравнивая человека к животному. Обозначенный подход акцентирует проблему реализации человека в социуме, где «самосознание личности... происходит как открытие самого себя через Другого. Цельность индивида и целостность личности достигаются... в неразрывном единстве индивидуального и социального, из которого и складывается уникальность каждого» [22, с. 326]

Данные тезисы обнажают новые ракурсы проблемы социального взаимодействия. Сегодня особое место отводится взаимодействию с людьми, ранее не имевшими возможности полноценно участвовать в созидании культурного пространства, людьми с ОВ3, а также отверженными социумом в силу каких-либо причин, так называемыми Другими. Осознавая, что в существующем «плюралистическом пространстве соседствуют самые разные Другие» [23, с. 29] и все они так или иначе взаимодействуют с социумом через «отторжение, присвоение и сосуществование» [23, с. 34], заметим, что сама возможность размышления над данной проблематикой является следствием серьезного изменения ценностных ориентиров современного общества.

В настоящее время уже можно осмыслить различные практики инклюзии, бытующие как в отечественном социокультурном пространстве, так и в общемировом. Различные модели социальной значимости людей с ОВЗ проявляют себя все более активно. Среди них - как давно существующие узкоспециализированные мероприятия (паралимпийские игры, начавшие свой отсчет с 1948 г.), так и всевозможные конкурсы, открытые сегодня для людей с ОВ3, позволившие заявить о себе значительному количеству творческих людей [24]. В этом потоке встречаются случаи, позволяющие нам поновому взглянуть на безграничный потенциал человеческих возможностей, открытый нам перкуссионисткой Эвелин Гленни, потерявшей слух в возрасте 11 лет, но не только не бросившей музыкальные занятия, но ярко заявившей о себе на весь мир [25]. 
Актуализация феномена инклюзии продиктована осознанием, что «все, кому нужен социум, кто по своим исходным характеристикам может быть обозначен как “Другой, отличный от меня”, имеют право на включение, приятие, полноценную социализацию, все, вне зависимости от состояния здоровья, пола, национальной и расовой принадлежности, способностей, образования, культурной идентичности, возраста, психологической зрелости и других отличительных черт» [26, с. 153]. Отличие человека от животного определяется, в первую очередь, наличием биосоциального начала, где биологическое неразрывно связано с социальным. Не требует доказательств утверждение, что для физиологического и социального взросления человека требуется гораздо больше усилий и времени, чем для других представителей животного мира. Казалось бы, данные выводы являются продуктом мысли общественных наук, отражая лишь социальный опыт человечества. Но существуют и вполне реальные нейробиологические механизмы, основанные на социальном взаимодействии, влияющие на человеческую жизнь.

Нейробиолог И. Бауэр в работе «Принцип человечности» обращает внимание на социальную сущность природных подсистем жизнедеятельности, что поистине революционно даже для современной науки [27]. Рассматривая системы мотивации с позиции нейробиологии как продукт эволюции, вырабатывающий нейромедиаторы (допамин, эндогенные опиоиды, окситоцин непосредственно влияют на способность человека к любым видам активности, в том числе двигательной), И. Бауэр приходит к выводу, что «естественной целью систем мотивации оказались социальная общность и позитивные, налаженные отношения с другими индивидами, причем это касается не только личных отношений, включая нежность и любовь, но и всех форм социального взаимодействия», таким образом, даже «с нейробиологической точки зрения мы являемся существами, созданными для социального взаимодействия и резонанса» [27, с. 27-28]. Современному миру лишь предстоит осознать всю значимость научного прорыва, произошедшего в начале XXI в., обусловленного тем, что общественные и биологические науки постепенно сходятся в выводах о человеческой природе.

Но не только эти новые повороты в научных представлениях заставляют серьезно задуматься над исследованием этой темы. На повестке дня еще одна особенность современной цивилизации как хранителя социокультурного опыта поколений, которая спровоцирована изменениями всех форм жизнедеятельности современного человека, обусловленными технологическим прорывом, и влияет на характер идентификации в начале третьего тысячелетия. На протяжении веков для нормальной жизнедеятель- ности в социуме человеку требовалось усвоить лишь одно основное правило: «Мы делаем как наши предки, ты должен делать как мы» [28, с. 169]. Наступило время, когда этот принцип перестает работать. Человечество наблюдает за глобальными изменениями, связанными с пониманием того, что многие процессы перестают поддаваться контролю, порой люди даже не замечают их или замечают только после того, как они спровоцировали ряд значимых событий.

Итак, мы растим, обучаем и воспитываем детей, но не придаем значение факту, что современные технологии они осваивают быстрее нас, лишь констатируя, что не в силах на это повлиять. Обыденной стала ситуация, когда учитель принимает новые технологии гораздо позже, чем его ученики. Очевидно одно: для человечества, если оно не смирилось с идеями апокалипсиса, настало время раскрыть глаза на ряд весьма значительных современных проблем. Придется понять, как они повлияют на нашу жизнь в дальнейшем, не только систематизировать поиск их решений, но и предвидеть их возникновение, вспомнив об опыте наших предков. Все это возможно только в обществе, ориентированном на социальную включенность и ответственность, которые, к сожалению, не всегда входят в систему ценностей, передаваемых посредством воспитания. И еще один фактор, на который необходимо обратить внимание. Если о детях с ОВЗ мы говорим сегодня уже достаточно много, то о воспитании одаренных детей с установкой на служение обществу, в противовес устоявшейся сегодня парадигме приумножения исключительно личного благополучия, практически не упоминается.

Резюмируя изложенное выше, подчеркнем, что только наличие социальной составляющей делает жизнь человека полноценной. В поисках своего места в обществе человек изменяется, развивается, совершенствует свои личностные характеристики. Социальное благо неотделимо от личного, личное же благо недостижимо без социального, ввиду того что исключение из общественной жизни в любых формах делает невозможной полноценную реализацию личности в современном мире. Современные психологи замечают, что сегодня достаточно часто встречаются люди, достигшие материального благополучия, но так и не получившие удовлетворения, не познавшие радости и счастья от гармоничных взаимоотношений. Именно об этих людях пишет В. Франкл, разделивший судьбу миллионов несчастных, оказавшихся в концентрационных лагерях в 1940-е гг., констатируя потерю смысловых ориентиров в жизни, ведущую к неврозам, а в самой трагичной ситуации - к суициду [29]. Он акцентирует внимание на том, что как это ни парадоксально, но наивысшая «потребность и вопрос о смысле жизни возникает именно тогда, когда человеку живется хуже некуда. Свидетельством тому являются 
умирающие из числа пациентов психиатра, а также уцелевшие бывшие узники концлагерей и лагерей для военнопленных» [29, с. 29]. Это приводит нас к выводу: каждый человек, появившийся на свет, должен иметь возможность найти свое место в мире людей по праву своего рождения человеком, должен быть включен в социум, где есть место и людям с ОВЗ, и иным Другим, трудно вписывающимся в привычные для нас рамки нормальности. Осознание данного факта способствует укреплению позиций инклюзии как ценностного ядра гуманизма.

\section{ОНТОЛОГИЯ ИНКЛЮЗИИ: ЧЕЛОВЕК И КУЛЬТУРА}

Ч еловек и культура - две фундаментальные философские категории, неразрывно связанные между собой. Культура есть отражение человеческой сущности, ибо «человек рождает культуру, проявляет себя в культуре, формирует всю систему культурного бытия мира» [30, с. 55]. Потому выпадение из культуры в эру тотальной симуляции, когда исчезают референты реальности и истины, заменяемые симулякрами [31, с. 21], подобно ситуации, связанной с отсутствием возможности созидать/творить культуру, девальвирует смыслы человеческой жизни. Обе ситуации содержат латентную уязвимость в виде нетолерантной реакции на социальные и культурные практики тех или иных людей. Взращивание в культуре инклюзивных идей как единственной возможности жить в «созвучии с ценностным микрокосмом Другого» [30, с. 24], как основы философии гуманизма, способствующей пестованию индивидуальности, уникальности и творческой созидательности личности, отражая происходящие сегодня тектонические сдвиги в ценностных ориентациях современного социума, предопределяет координаты будущего человеческой цивилизации - эпохи инклюзии.

Человек, преобразуя свое бытие, неустанно творит культуру, которая «предстает прежде всего как средство межчеловеческой коммуникации и общения в пространстве и времени» [32, с. 31], подчеркнем, что как и сам «гуманизм может рассматриваться... как определенный вид культуры» [33, с. 232], так и в недрах инклюзии заключены серьезные ресурсы для взращивания культуры межличностного взаимодействия, где «первостепенной ценностью становится уход от идеологии соперничества и провозглашение идеологии сотрудничества во всеобщем значении приятия “особливости” друг друга» [30, с. 57], признания значимости уникальности как себя, так и Другого. Вся суть созидания культурного бытия заключается в укреплении позиций идеи уникальности как главной ценности человеческого воплощения, где именно «человек и есть сама цель, абсолютная ценность, где воплощенная жизнь есть высшее благо - дар Вселенной для реализации самого себя, для приятия Другого, для признания Другости как уникальной сущности в самом себе» [30, с. 23].

Устремляясь к реализации уникального личностного потенциала, мы неизменно возвращаемся к размышлениям о смысле жизни, о том, с какой целью и для чего существуем. Обращаясь к мыслителям, исследующим данную проблематику, вернемся к точке зрения В. Франкла. В чем видел смысл жизни этот мужественный врач, размышляя над происходящим перед его глазами? Понимание важности собственного предназначения, задачи, стоящей перед индивидом, является абсолютным двигателем для личности, столкнувшейся с жизненными трудностями. «Особенно ярко это проявляется в том случае, когда человеку эта задача кажется будто специально предназначенной для него лично, когда она представляет собой нечто вроде “миссии”. Такая задача помогает человеку ощутить свою незаменимость, жизнь его приобретает ценность уже потому только, что она неповторима» [29, с. 181].

Соглашаясь с данным суждением, приведем в подтверждение историю становления в России инклюзивного образования. Именно осознание «мессианского» характера своей деятельности, впоследствии поспособствовавшей распространению идей инклюзии в нашей стране, позволило группе родителей детей-инвалидов не только инициировать создание серьезной общественной организации «Ковчег», организовать первую инклюзивную школу, но и помочь многим родителям поверить в то, что их дети тоже могут стать частью социума, девиз которого «Мы - одна семья» [34]. Таким же примером «мессианства» являются жизнь и творчество Б.3. Кривошея [7], посвятившего более 40 лет своей жизни защите прав людей с ментальными нарушениями. Его книги ${ }^{1}$, повествующие без прикрас о тяготах жизни инвалидов в современном российском обществе, - социокультурный набат, призванный разбудить всех тех, кто до сих пор считает, что слова «дебил» и «идиот» в адрес людей с ментальными нарушениями не являются оскорблением, что на людей с нарушениями в развитии можно показывать пальцем или не замечать инвалида-колясочника, которому требуется помощь, чтобы подняться по ступенькам. Сегодня российскому обществу, не-

1 «Несуществующий народ» (о мире людей, живущих в изоляции), «ПНИ на дороге в никуда» (о жизни в психоневрологических интернатах), «Миша Карусель» (истории «особых» людей и размышления автора об их потребности в любви, понимании и приятии), «Голоса сердец» (очерки о тех, кто посвятил свою жизнь помощи инвалидам), «Хочу жить завтра. Беседы с сыном» (разговор с сыном о незаурядных людях из окружения автора, сопровождаемый бесконечной тревогой отца за будущее «особого» сына) [8]. 
сомненно, требуется такая «прививка» от невежества, поскольку комфортное существование в социуме возможно только в том случае, если этот социум готов тебя слушать и слышать.

В. Франкл подчеркивает: «...смысл человеческой личности всегда связан с обществом, в своей ориентации на общество смысл индивида трансцендирует себя... И наоборот, смысл общества в свою очередь конституируется существованием индивидов» [29, с. 15]. Из этого следует, что исключение человека из социальной жизни, невозможность созидать культуру, творить на благо социума, быть принятым обществом со всеми своими особенностями не только унижают достоинство личности, но и разрушают истинно человеческое начало как в социальном, так и в индивидуальном контексте. Готовность включить каждого человека в социум, увидеть его особые социокультурные и образовательные потребности, дать возможность реализовать свой уникальный творческий потенциал неизменно способствует преодолению деградации человеческого в человеке, и мы свидетели, как ростки этого понимания, пусть и очень медленно, всходят в современной России.

Инклюзивный подход, становясь ценностным императивом, в той или иной степени формируя новое мировоззрение, завоевывает сегодня весь мир. Суть его - «процесс поиска собственной уникальной творческой природы», а способность к «творческой радости», получаемой от создания уникального творческого продукта, является своего рода лакмусовой бумажкой, определяющей «правильность выбранного пути в acceptio civitas (принимающее общество)» [30, с. 62]. Результат, устремленный к завершенности, сдавая свои позиции, уступает место таинству творчества, потому что смыслом данной деятельности становится процесс сотворчества как основы для «развития творческой личности участника, т. е. становления его субъективности и рефлексивности» [35], для трансляции ценностей и смыслов в культуру, для умения разбудить в себе полилоговое начало в стремлении к постулированию парадигмы Мы [32]. Соглашаясь с тем, что эстетическая составляющая стимулирует становление социокультурной общности, заметим, что именно таинство сотворчества позволяет нам войти в созвучие с миром Другого, а значит, понять и принять его как личность.

Но главным, почти ошеломляющим выводом в утверждении творческого начала как важнейшей составляющей жизни индивида становится ее биологическая природа, утверждаемая в исследованиях И. Бауэра: «Креативность в области культуры никоим образом не проявление роскоши, а выражение поиска того, на что мы ориентированы нашей глубинной биологической сутью. К культурным формам жизни относятся не только искусства, но и мно- гообразные виды социального взаимодействия. Они охватывают воспитание в наших детях гуманности, образование, этический менеджмент в сфере экономики и готовность помогать друг другу в материальных бедах и в случаях болезни» [27, с. 124]. Духовные потребности у нас и сегодня могут быть отодвинуты на второй план, но биологические, совершенно однозначно, игнорировать не получится.

Современное общество, преодолевая границы социальной эксклюзии, устремляется к новым горизонтам инклюзивного бытия, где есть место каждому, где Другость, в том числе связанная с личностным кризисом аутентичности (я есть Другой), стимулирует новые возможности для воплощения собственной сущности в процессе самоотождествления. И здесь вновь уместно напомнить еще одно высказывание В. Франкла: «Человек во многом похож на скульптора, который работает с бесформенным камнем для того, чтобы его материал приобретал все более зримую форму. Человек ваяет свою жизнь из того материала, который дан ему судьбой: в творчестве, в переживаниях или страдании он созидает ценности собственной жизни - каждый по мере своих сил формирует или ценности творчества, или ценности переживания, или ценности отношения» [29, с. 193]. Все люди, в том числе и с ОВЗ, к которым по праву первых, ввиду невероятной сложности их бытия, обращены идеи инклюзии, творят свое собственное произведение под названием «жизнь», где одним удается серьезно заявить о себе, несмотря на множественные проблемы, другим же предначертан путь ежеминутного преодоления трудностей, уготованных им судьбой. Но хочется верить, что XXI в. станет началом отсчета эпохи инклюзии, когда доказывать право на счастье, любовь, творчество, понимание, благополучие и социальное признание будет не нужно уже никому. Предвестником этой эпохи звучат слова философа ХХ в., деятеля гуманистического движения П. Куртца: «Я утверждаю, что именно всепланетная гуманистическая цивилизация составит основу всеобщего согласия, породит новую глобальную этику, обосновывающую и провозглашающую нашу ответственность перед мировым сообществом, преодолевающую характерные для прошлого узкие этнические, расовые, религиозные и национальные пристрастия...» [2]. Эпоха инклюзии как рупор глобальной этики, провозглашающий согласие и сотворчество основой бытия человека как единственного существа на планете, нуждающегося в социальном воплощении, уже зовет нас с собой. Остается только услышать ее и сделать шаг навстречу Другому.

\section{Список источников}

1. Курти П. Инфомедийная революция и перспективы глобального гуманизма // Здравый смысл. 2002. № 3 (24). С. 3-8. 
2. Курти П. Гуманизм и скептицизм - парадигмы культуры третьего тысячелетия [Электронный ресурс] // Здравый смысл. 2000. № 17. URL: http://humanism. al.ru/ru/magazine.phtml?issue=2000.17-01 (дата обращения: 28.12.2017).

3. Судакова Н.Е. Философия инклюзии: пути в принимающее общество // Музыка в информационном пространстве культуры третьего тысячелетия: проблемы, мнения, перспективы : сб. науч. тр. Москва : РГСУ, 2012. Вып. VII. С. 160-164.

4. Шеманов А.Ю., Востров И.М., Егорова В.А. Творческая деятельность и инклюзия // Современная зарубежная психология. 2013. № 3. С. 5-18.

5. Шеманов А.Ю. Политика инклюзии и этническая идентичность в контексте проблемы открытости другому // Обсерватория культуры. 2016. Т. 13, № 6. C. 652-659. DOI: 10.25281/2072-3156-2016-13-6652-659.

6. Кудишина А.А. Гуманизм - феномен современной культуры. Москва : Академический проект, 2005. 504 c.

7. Борис Кривошей - «Хочу жить завтра» [Электронный ресурс] // Санкт-Петербурская ассоциация общественных объединений родителей детей-инвалидов «ГАООРДИ». Электронная версия. URL: http:// gaoordi.ru/boris-krivoshej-hochu-zhit-zavtra/ (дата обращения: 28.12.2017).

8. Несуществующий народ Бориса Кривошея [Электронный ресурс] // Planeta - Российская краудфандинговая платформа. URL: https://planeta.ru/campaigns/ krivoshey (дата обращения: 28.12.2017).

9. Кондаков И.В., Соколов К.Б., Хренов Н.А. Цивилизационная идентичность в переходную эпоху : культурологический, социологический и искусствоведческий аспекты. Москва : Прогресс-Традиция, 2011. 1024 с.

10. Астафьева О.Н. Культурная политика: динамика теоретических подходов и фундаментальных концептуализаций // Исторические повороты культуры : сб. науч. ст. (к 70-летию проф. И.В. Кондакова) / общ. ред. и сост. О.Н. Астафьевой. Москва : Согласие, 2018. С. $86-102$.

11. Эпштейн М.Н. Транскультура и трансценденция: личность и вещь как странники в иное // И.М. Болотников. Только уникальное глобально : личность и управление : культура и образование : сб. статей в честь 60-летия проф. Г.Л. Тульчинского. Санкт-Петербург : СПбГУКИ, 2007. С. 90-102.

12. Astafyeva O.N., Belyakova I.G., Sudakova N.E. Theoretical Studies of Mass Culture as a Self-Developing System in the Context of the Tasks of Russia's Cultural Policy // Eurasian Journal of Analytical Chemistry. 2017. Vol. 12, no. $7 \mathrm{~b}$. Interdisciplinary Perspective on Sciences. P. 1475-1481. DOI: 10.12973/ejac.2017.00275a.

13. Banerji M., Dailey R. A Study of the Effects of an Inclusion Model on Students with Specific Learning Disabilities // Journal of Learning Disabilities. 1995. Vol. 28, № 8. P. 511-522.
14. Corbett J. Inclusive Education and School Culture // International Journal of Inclusive Education. 1999. Vol. 3, no. 1. P. 53-61.

15. Bennett T., Deluca D., Bruns D. Putting Inclusion into Practice: Perspectives of Teachers and Parents // Exceptional Children. 1997. Vol. 64, № 1. P. 115-131. DOI: $10.1177 / 001440299706400108$.

16. Education \& Children with Special Needs : From Segregation to Inclusion / by ed. M. Alur, S. Hegarty. Thousand Oaks (CA, USA) : Sage Publications, Inc., 2002. 220 p.

17. Малофеев Н.Н. Похвальное слово инклюзии или речь в защиту самого себя // Альманах института коррекционной педагогики. 2011. № 15. С. 3-14.

18. Астафьева О.Н., Синецкий С.Б. Философские и прикладные аспекты культурной политики на поселенческом уровне // Вестник культуры и искусств. 2017. № 4(52). C. $70-80$.

19. Малофеев Н.Н., Шматко Н.Д. Базовые модели интегрированного обучения // Дефектология. 2008. № 6. C.71-78.

20. World Report on Disability 2011 [Электронный ресурс] // World Health Organization. URL: https:// www.who.int/disabilities/world_report/2011/report. pdf (дата обращения: 28.12.2017).

21. Шеманов А.Ю. Самоидентификация человека и культура : монография. Москва : Академический проект, 2007. 479 c.

22. Астафьева О.Н., Резник Ю.М. Жизнь в настоящем и настоящее в жизни // Личность. Культура. Общество. 2011. Т. 13, № 3. С. 318-339.

23. Шапинская Е.Н. Образ Другого в текстах культуры. Москва : Красанд, 2012. 216 с.

24. Mandy Harvey: Deaf Singer Earns Simon's Golden Buzzer With Original Song - America's Got Talent 2017 [Видеозапись] // YouTube : канал «America’s Got Talent». 2017. 6 июня. URL: https://www.youtube. com/watch?v=ZKSWXzAnVe0 (дата обращения: 28.12.2017).

25. Эвелин Гленни учит слушать [Видеозапись] // YouTube : канал «TED». 2007. 14 мая. URL: https:// www.youtube.com/watch?v=IU3V6zNER4g (дата обращения: 28.12.2017).

26. Судакова Н.Е. Философская рефлексия инклюзии как феномена современной культуры: навстречу Другому // Исторические, философские, политические и юридические науки, культурология и искусствоведение : вопросы теории и практики. 2016. № 111(73). С. $152-154$.

27. Бауэр И. Принцип человечности: почему мы по своей природе склонны к кооперации / [пер. с нем. И. Тарасова]. Санкт-Петербург : Изд-во Вернера Регена, 2009. 150 c.

28. Дорожкин А.М., Тимофеева О.В. Особенности трансляции духовных ценностей // Вестник Нижегородского университета им. Н.И. Лобачевского. Серия: Социальные науки. 2014. № 2(34). С. 169-174. 
29. Франкл В. Человек в поисках смысла : сборник / пер. с англ. и нем. ; общ. ред. Л.Я. Гозмана, Д.А. Леонтьева ; вст. ст. Д.А. Леонтьева. Москва : Прогресс, 1990. $368 \mathrm{c}$.

30. Судакова Н.Е., Сапельников Д.С., Попова М.В. Творчество в контексте культурфилософского осмысления и педагогического моделирования мировоззрения личности : монография. Москва : Буки-Веди, 2016. $184 \mathrm{c}$.

31. «Нормальная аномия» в России и современном мире : коллектив. монография / [Н.Н. Зарубина и др.] ; под общ. ред. С.А. Кравченко. Москва : МГИМО-Университет, 2017. 281 с.

32. Межуев В.М. Идея культуры : очерки по философии культуры. Москва : Прогресс-Традиция, 2006. 408 с.
33. Решетников В.А. Специфика современного гуманизма как культуры // Современный гуманизм: проблемы и перспективы / под общ. ред. В.А. Решетникова. Иркутск : Изд-во Иркутск. ун-та, 2004. C. 227-246.

34. История РООИ «Ковчег» [Электронный ресурс] // Региональная общественная организация инвалидов и родителей детей-инвалидов «Ковчег» (РООИ «Ковчег»). URL: http://нашковчег.pф/history.html (дата обращения: 28.12.2017).

35. Шеманов А.Ю., Макаева Д.Э. Творчество и инклюзивная культура образовательной организации // Психологическая наука и образование psyedu.ru. 2016. T. 8, № 1. C. 24-34. DOI: 10.17759/ psyedu.2016080103.

\section{Inclusion as a Value Core of the Philosophy of Humanism}

\section{Natalia E. Sudakova}

Russian Presidential Academy of National Economy and Public Administration, 84, Vernadskogo Av., Moscow, 119606, Russia

E-mail: sovetnik.imtp@mail.ru

\begin{abstract}
Sociocultural transformations that affect today all layers of human existence exacerbate the problem of including the Other into the social life. Inclusion - a new phenomenon of culture - appears as a response to the intolerant attitude of a person to another person. The need for cultural philosophical reflection on inclusion predetermines the relevance of this work. Inclusive practices, whose common understanding draws attention to the destructive nature of social interaction of the society and the individual with disabilities, require a revision of their senseforming coordinates.
\end{abstract}

The renewed understanding of inclusion as the nucleus of the philosophy of humanism expands the scope of the view that technologies the society uses for satisfying special sociocultural and educational needs should be addressed to people with disabilities, shifting the emphasis towards recognizing the "singularity" / uniqueness of each individual for the further development of human civilization. The author's approach, giving everyone unlimited opportunities for self-fulfillment, immerses a person into the amazing mystery of creativity, striving to create the joy of co-existence. Emphasis is placed on the understanding that creativity is a process of social interaction, where deprivation of the supremacy of the competition and effectiveness paradigms prevailing in the modern society contributes to overcoming the negative practices of self-awareness / accepting the Other as a carrier of abnormality, as well as to affirming the importance of the individual's "singu- larity" / uniqueness for the social well-being of people and society. The presented approach to inclusion, accumulating the conceptual ideas of the philosophy of humanism, allows a person to discover a unique beginning in themselves, which promotes both the socialization of the personality and the acquisition of new reasons for existence. Appealing to the latest research in the field of neurobiology proving the social nature of man is dictated by the insufficient attention of the modern society to education of a socially responsible person. The social fullness of a person's life, leading to the assertion of one's own unique nature by including in the process of co-creation, contributing to the overcoming of the life meaning search crisis, harmonizes the vital activity of all social institutions, including those in the scale of humanity.

Key words: inclusion, humanism, man, society, culture, identity, Other, people with disabilities, mystery of creativity.

Citation: Sudakova N.E. Inclusion as a Value Core of the Philosophy of Humanism, Observatory of Culture, 2018 , vol. 15 , no. 1 , pp. $21-31$. DOI: $10.25281 / 2072-$ 3156-2018-15-1-21-31.

\section{References}

1. Kurtz P. Infomedia Revolution and the Prospects of the Planetary Humanism, Zdravyi smysl [Common Sense], 2002, no. 3 (24), pp. 3-8 (in Russ.).

2. Kurtz P. Humanism and Skepticism - The Cultural Paradigms of the Third Millennium, Zdravyi smysl [Common Sense], 2000, no. 17 (in Russ.). Available at: http://humanism.al.ru/ru/magazine.phtml?issue=2000.17-01 (accessed 28.12.2017).

3. Sudakova N.E. Filosofiya inklyuzii: puti v prinimayushchee obshchestvo [Philosophy of Inclusion: Pathways to the Host Society], Muzyka $v$ informatsionnom prostranstve kul'tury tret'ego tysyacheletiya: problemy, mneniya, perspektivy: sb. nauch. tr. [Music in the Information 
Space of the Culture of the Third Millennium: Problems, Opinions, Perspectives: collected scientific works]. Moscow, RGSU Publ., 2012, issue VII, pp. 160-164.

4. Shemanov A.Yu., Vostrov I.M., Egorova V.A. Creative Activity and Inclusion, Sovremennaya zarubezhnaya psikhologiya [Journal of Modern Foreign Psychology], 2013, no. 3, pp. 5-18 (in Russ.).

5. Shemanov A.Yu. Inclusion Policy and Ethnic Identity in the Context of Openness to the Other, Observatoriya kul'tury [Observatory of Culture], 2016, vol. 13, no. 6, pp. 652-659 (in Russ.). DOI: 10.25281/2072-31562016-13-6-652-659.

6. Kudishina A.A. Gumanizm - fenomen sovremennoi kul'tury [Humanism Is a Phenomenon of Modern Culture]. Moscow, Akademicheskii Proekt Publ., 2005, $504 \mathrm{p}$.

7. Boris Krivoshei - "Khochu zhit' zavtra" [Boris Krivoshei - "I Want to Live Tomorrow"], Sankt-Peterburskaya assotsiatsiya obshchestvennykh ob"edinenii roditelei detei-invalidov "GAOORDI" [St. Petersburg Association of Public Obligations of Parents of Children with Disabilities "GAOORDI"]. Available at: http://gaoordi.ru/boris-krivoshej-hochu-zhit-zavtra/ (accessed 28.12.2017).

8. Nesushchestvuyushchii narod Borisa Krivosheya [The Nonexistent People of Boris Krivoshei], Planeta - Rossiiskaya kraudfandingovaya platforma [Planeta - Russian Crowdfunding Platform]. Available at: https://planeta. $\mathrm{ru}$ /campaigns/krivoshey (accessed 28.12.2017).

9. Kondakov I.V., Sokolov K.B., Khrenov N.A. Tsivilizatsionnaya identichnost' $v$ perekhodnuyu epokhu: kul'turologicheskii, sotsiologicheskii i iskusstvovedcheskii aspekty [Civilization Identity in the Transition Period: Culturological, Sociological and Art Aspects]. Moscow, Progress-Traditsiya Publ., 2011, 1024 p.

10. Astafyeva O.N. Kul'turnaya politika: dinamika teoreticheskikh podkhodov i fundamental'nykh kontseptualizatsii [Cultural Policy: Dynamics of Theoretical Approaches and Fundamental Conceptualizations], Istoricheskie povoroty kul'tury: sb. nauch. st. (k 70-letiyu prof. I.V. Kondakova) [Historical Twists of Culture: collected scientific articles]. Moscow, Soglasie Publ., 2018, pp. 86102.

11. Epshtein M.N. Transkul'tura i transtsendentsiya: lichnost' i veshch' kak stranniki v inoe [Transculture and Transcendence: The Person and the Thing as Travellers into the Different], I.M. Bolotnikov. Tol'ko unikal'noe global'no: lichnost' i upravlenie: kul'tura i obrazovanie: sb.statei $v$ chest' 60-letiya prof. G.L. Tul'chinskogo [I.M. Bolotnikov. Only the Unique Is Global. Personality and Management. Culture and Education: collected articles in honor of the 60th anniversary of prof. G.L. Tulchinsky]. St. Petersburg, SPbGUKI Publ., 2007, pp. 90-102.

12. Astafyeva O.N., Belyakova I.G., Sudakova N.E. Theoretical Studies of Mass Culture as a Self-Developing System in the Context of the Tasks of Russia's Cultural Policy, Eurasian Journal of Analytical Chemistry, 2017, vol. 12, no. 7b. Interdisciplinary Perspective on Sciences, pp. 1475-1481. DOI: 10.12973/ejac.2017.00275a.

13. Banerji M., Dailey R. A Study of the Effects of an Inclusion Model on Students with Specific Learning Disabilities, Journal of Learning Disabilities, 1995, vol. 28, no. 8, pp. $511-522$.

14. Corbett J. Inclusive Education and School Culture, International Journal of Inclusive Education, 1999, vol. 3, no. 1, pp. 53-61.

15. Bennett T., Deluca D., Bruns D. Putting Inclusion into Practice: Perspectives of Teachers and Parents, Exceptional Children, 1997, vol. 64, no. 1, pp. 115-131. DOI: 10.1177/001440299706400108.

16. Alur M., Hegarty S. (eds). Education E Children with Special Needs: From Segregation to Inclusion. Thousand Oaks (CA, USA), Sage Publications, Inc., 2002, 220 p.

17. Malofeev N.N. A Laudatory Word for Inclusion or a Speech of Self-Defense, Al'manakh instituta korrektsionnoi pedagogiki [Almanac of the Institute of Special Education], 2011, no. 15, pp. 3-14 (in Russ.).

18. Astafyeva O.N., Sinetsky S.B. Philosophical and Applied Aspects of Cultural Policy at the Settlement Level, Vestnik kul'tury $i$ iskusstv [Culture and Arts Herald], 2017, no. 4(52), pp. 70-80 (in Russ.).

19. Malofeev N.N., Shmatko N.D. Basic Models of Integrated Learning, Defektologiya [Defectology], 2008, no. 6, pp. $71-78$ (in Russ.).

20. World Report on Disability 2011, World Health Organization. Available at: https://www.who.int/disabilities/ world_report/2011/report.pdf (accessed 28.12.2017).

21. Shemanov A.Yu. Samoidentifikatsiya cheloveka i kul'tura: monografiya [Human Self-Identification and Culture]. Moscow, Akademicheskii Proekt Publ., 2007, 479 p.

22. Astafyeva O.N., Reznik Yu.M. Life in the Real and the Real in Life, Lichnost'. Kul'tura. Obshchestvo [Personality. Culture. Society], 2011, vol. 13, no. 3, pp. 318-339 (in Russ.).

23. Shapinskaya E.N. Obraz Drugogo v tekstakh kul'tury [The Image of the Other in the Texts of Culture]. Moscow, Krasand Publ., 2012, 216 p.

24. Mandy Harvey: Deaf Singer Earns Simon's Golden Buzzer With Original Song - America's Got Talent 2017, YouTube channel "America's Got Talent". 2017. 6 June. Available at: https://www.youtube.com/ watch?v=ZKSWXzAnVe0 (accessed 28.12.2017).

25. Evelin Glenni uchit slushat' [Evelyn Glennie: How to Truly Listen], YouTube channel “TED”. 2007. 14 May. Available at: https://www.youtube.com/watch?v=IU3V6zNER4g (accessed 28.12.2017)

26. Sudakova N.E. Philosophical Reflection of Inclusion as a Phenomenon of Modern Culture: Towards the Other, Istoricheskie, filosofskie, politicheskie i yuridicheskie nauki, kul'turologiya i iskusstvovedenie: voprosy teorii i praktiki [Historical, Philosophical, Political and Law Sciences, Culturology and Study of Art. Issues of Theory and Practice], 2016, no. 11-1(73), pp. 152-154 (in Russ.).

27. Bauer J. Printsip chelovechnosti: pochemu my po svoei prirode sklonny k kooperatsii [The Principle of Humanity: 
Why We Are Inherently Inclined to Cooperation]. St. Petersburg, Vernera Regena Publ., 2009, 150 p.

28. Dorozhkin A.M., Timofeeva O.V. Special Aspects of the Transferring of Inner Values, Vestnik Nizhegorodskogo universiteta im. N.I. Lobachevskogo. Seriya: Sotsial'nye nauki [Bulletin of the Lobachevsky State University of Nizhny Novgorod. Series: Social Sciences], 2014, no. 2(34), pp. 169-174 (in Russ.).

29. Frankl V. Man's Search for Meaning. Moscow, Progress Publ., 1990, 368 p. (in Russ.).

30. Sudakova N.E., Sapelnikov D.S., Popova M.V. Tvorchestvo $v$ kontekste kul'turfilosofskogo osmysleniya i pedagogicheskogo modelirovaniya mirovozzreniya lichnosti: monografiya [Creativity in the Context of Cultural Philosophical Understanding and Pedagogical Modeling of the Worldview of the Individual: monograph]. Moscow, Buki-Vedi Publ., 2016, 184 p.

31. Kravchenko S.A. (ed.) "Normal'naya anomiya" $v$ Rossii $i$ sovremennom mire: kollekt. monografiya ["Normal Anomie" in Russia and the Modern World: collective monograph]. Moscow, MGIMO-Universitet Publ., 2017, 281 p.
32. Mezhuev V.M. Ideya kul'tury: ocherki po filosofii kul'tury [The Idea of Culture: Essays on the Philosophy of Culture]. Moscow, Progress-Traditsiya Publ., 2006, 408 p.

33. Reshetnikov V.A. Specificity of Modern Humanism as Culture, Sovremennyi gumanizm: problemy i perspektivy [Modern Humanism: Problems and Prospects]. Irkutsk, Irkutskogo Universiteta Publ., 2004, pp. 227-246 (in Russ.).

34. Istoriya ROOI "Kovcheg” [The History of ROOI "Kovcheg”, Regional'naya obshchestvennaya organizatsiya invalidov i roditelei detei-invalidov "Kovcheg" (ROOI "Kovcheg”) [Regional Public Organization for Disabled People and Parents of Disabled Children "Kovcheg" (ROOI "Kovcheg”)]. Available at: http://xn--80aedhxqj7ef.xn--p1ai/ history.html (accessed 28.12.2017).

35. Shemanov A.Yu., Makaeva D.E. Creativity and Inclusive Culture of the Educational Organization, Psikhologicheskaya nauka i obrazovanie psyedu.ru [Psychological Science and Education www.psyedu.ru], 2016, vol. 8, no. 1, pp. 24-34 (in Russ.). DOI: 10.17759/ psyedu.2016080103.

НОВИНКА

Белякова И.Г. Эволюция моделей межкультурной коммуникации в многоязычном пространстве глобального информационного общества. Ногинск : АНАЛИТИКА РОДИС, 2017. 154 с.

Монография посвящена особенностям межкультурной коммуникации в современном глобализированном информационном пространстве. Автор раскрывает особенности взаимодействия национальных и языковых картин мира, освещает острые вопросы мультикультурализма и формулирует требования современности к построению международных отношений в контексте глобальной коммуникации. Раскрывается глубокая актуальность изучения иностранных языков, в частности, английского как lingua franca современной науки, культуры, межнационального общения. В рамках компетентностного подхода автор уделяет особое внимание межкультурной комтепентности.

Книга рекомендуется специалистам по культурологии, комуникативистике, социальной философии и всем тем, кому небезынтересны закономерности обмена информацией в глобализирующемся мире. 